\title{
Soluble vascular endothelial growth factor receptor-3 suppresses lymphangiogenesis and lymphatic metastasis in bladder cancer
}

Hanseul Yang ${ }^{1 \dagger}$, Chan Kim ${ }^{1 \dagger}$, Min-Ju Kim², Reto A Schwendener ${ }^{3}$, Kari Alitalo ${ }^{4}$, Warren Heston ${ }^{5}$, Injune Kim', Wun-Jae Kim ${ }^{2^{*}}$ and Gou Young Koh ${ }^{1^{*}}$

\begin{abstract}
Background: Most bladder cancer patients experience lymphatic metastasis in the course of disease progression, yet the relationship between lymphangiogenesis and lymphatic metastasis is not well known. The aim of this study is to elucidate underlying mechanisms of how expanded lymphatic vessels and tumor microenvironment interacts each other and to find effective therapeutic options to inhibit lymphatic metastasis.
\end{abstract}

Results: The orthotopic urinary bladder cancer (OUBC) model was generated by intravesical injection of MBT-2 cell lines. We investigated the angiogenesis, lymphangiogenesis, and CD $11 \mathrm{~b}^{+} / \mathrm{CD} 68^{+}$tumor-associated macrophages (TAM) by using immunofluorescence staining. OUBC displayed a profound lymphangiogenesis and massive infiltration of TAM in primary tumor and lymphatic metastasis in lymph nodes. TAM flocked near lymphatic vessels and express higher levels of VEGF-C/D than CD11b- cells. Because VEGFR-3 was highly expressed in lymphatic vascular endothelial cells, TAM could assist lymphangiogenesis by paracrine manner in bladder tumor. VEGFR-3 expressing adenovirus was administered to block VEGF-C/D signaling pathway and clodronate liposome was used to deplete TAM. The blockade of VEGF-C/D with soluble VEGF receptor-3 markedly inhibited lymphangiogenesis and lymphatic metastasis in OUBC. In addition, the depletion of TAM with clodronate liposome exerted similar effects on OUBC.

Conclusion: VEGF-C/D are the main factors of lymphangiogenesis and lymphatic metastasis in bladder cancer. Moreover, TAM plays an important role in these processes by producing VEGF-C/D. The inhibition of lymphangiogenesis could provide another therapeutic target to inhibit lymphatic metastasis and recurrence in patients with invasive bladder cancer.

\section{Background}

Bladder cancer ranks as the second most common genitourinary cancer and is associated with frequent distant metastasis at the time of both initial diagnosis and recurrence $[1,2]$. Even though radical cystectomy and lymph node dissection may be curative, about $50 \%$ of patients with muscle-invasive bladder cancer eventually experience recurrence and metastases within 2 years of

\footnotetext{
*Correspondence: wjkim@chungbuk.ac.kr; gykoh@kaist.ac.kr

+ Contributed equally

'National Research Laboratory of Vascular Biology and Graduate School of Medical Science and Engineering, Korea Advanced Institute of Science and Technology (KAIST), Daejeon, 305-701, Republic of Korea

${ }^{2}$ Department of Urology, College of Medicine, Institute for Tumor Research,

Chungbuk National University, Cheongju, 360-711, Republic of Korea

Full list of author information is available at the end of the article
}

surgery, and most of them die of the disease [1]. In patients with bladder cancer, the presence of metastasis in regional lymph node is a strong indicator of high recurrence ( $\sim 55 \%$ at 5 years after cystectomy) and relatively poor survival rate $(\sim 45 \%$ at 5 years after cystectomy) [3,4]. Intriguingly, patients and mice with bladder cancer display profound lymphatic vessels in the peripheral and central regions, which could be actively involved in lymphatic metastasis to lymph node $[5,6]$. However, the underlying causes and driving forces of the expansion of lymphatic vessels in bladder cancer and underlying mechanisms of how the expanded lymphatic vessels are involved in bladder cancer metastasis to lymph nodes are poorly understood.

\section{C) Biomed Central}


New lymphatic vessel formation, lymphangiogenesis, is potently induced by lymphangiogenic growth factors such as vascular endothelial growth factor (VEGF)-C and VEGF-D (VEGF-C/D) through binding and activation of their receptor tyrosine kinase, VEGF receptor-3 (VEGFR-3) [7,8]. Proliferation, sprouting, expansion, enlargement and permeability of lymphatic vessels are largely affected by VEGF-C/D, and these processes facilitate cancer cell migration into the lymphatic vessels and spread to sentinel lymph node (SLN) [9-11]. Accordingly, blocking the VEGF-C/D-VEGFR-3 signaling pathway suppresses tumor lymphangiogenesis and lymph node metastasis in several tumor models [12-15]. These reports indicate that VEGF-C/D-mediated VEGFR-3 activation contributes to not only lymphatic vessel growth but also tumor cell dissemination via lymphatic vessels. In addition, VEGF-C/D is highly expressed in patients with bladder cancer [16,17] and this expression is closely related to lymph node metastasis, but it has an inconsistent relationship with prognosis and survival rate. Yet, causative relationship between expression of VEGF-C/D, lymphangiogenesis and lymph node metastasis in the bladder cancer is not exactly known. It is known that $\mathrm{CD}_{11} \mathrm{~b}^{+}$tumor-associated macrophages (TAM) mainly express genes of the M2 type such as CD68, F4/80 and VEGFR-1, and is actively involved in tumor invasion and progression [18]. Accumulating evidences indicate that TAM takes considerable part in promoting tumor angiogenesis and progression by abundant secretions of diverse angiogenic and lymphangiogenic growth factors [18-23]. However, involvement of TAM in lymphangiogenesis and lymphatic metastasis to SLN is unknown in the bladder cancer. Therefore, in this study, we investigated roles of VEGF-C/D and involvement of TAM in tumor lymphangiogenesis and lymphatic metastasis in the murine orthotopic urinary bladder cancer (OUBC) model. We found that OUBC induces profound lymphangiogenesis in the tumor and SLN and substantial lymphatic metastasis to SLN through VEGF-C/D-VEGFR-3 signaling pathway. Furthermore, $\mathrm{CD} 11 \mathrm{~b}^{+} / \mathrm{CD} 68^{+} \mathrm{TAM}$ was largely infiltrated around the tumor lymphatic vessels, and they were closely involved in the OUBC-induced lymphangiogenesis and lymphatic metastasis, possibly through secretary lymphangiogenic factors such as VEGF-C/D. Our findings provide a novel insight and useful treatment strategy how to control lymphatic metastasis in the patients with bladder cancer through suppression of VEGFR-3 signaling pathway.

\section{Methods}

\section{Generation of OUBC mouse model}

Eight-ten weeks old female $\mathrm{C} 3 \mathrm{H} / \mathrm{HeN}$ mice were purchased from the Orient Bio Inc. (Seongnam, Korea).
Animal care and experimental procedures were performed under approval from the Animal Care Committees of KAIST. The murine bladder cancer cell line MBT-2 was originally obtained from Dr. Timothy Ratliff (University of Iowa, Iowa City, Iowa). The cell line initially originated from a transplantable N-[4-(5-nitro-2furyl)-2-thiazolyl]-formamide-induced bladder tumor in a C3H mouse [24]. The MBT-2 cells were cultured in DMEM (Lonza, Walkersville, MD) containing 10\% heatinactivated fetal bovine serum (Cambrex, Walkersville, MD), $50 \mathrm{U} / \mathrm{ml}$ penicillin and $50 \mathrm{mg} / \mathrm{ml}$ streptomycin (Invitrogen, Grand Island, NY) in plastic tissue culture dishes at $37^{\circ} \mathrm{C}$ in a humidified atmosphere of $5 \% \mathrm{CO}_{2}$. The cells were trypsinized and resuspended to a single cell suspension in PBS. The mice were anesthetized with an intramuscular injection of ketamine $(100 \mathrm{mg} / \mathrm{kg})$ and xylazine $(10 \mathrm{mg} / \mathrm{kg})$. A $24 \mathrm{G}$ catheter (Becton Dickinson Korea Ltd., Korea) was inserted into the bladder through the urethra. The bladder epithelial layer was wounded with $100 \mu \mathrm{l}$ of $0.1 \mathrm{~N} \mathrm{HCl}$ and $\mathrm{NaOH}$ to improve tumor cell implantation. $1 \times 10^{6}$ suspended MBT- 2 cells in $100 \mu \mathrm{l}$ of PBS were injected into the bladder cavity.

\section{Histologic and morphometric analysis}

Four weeks after MBT-2 cell implantation, bladder and SLN were sampled. For whole-mount staining, tissue samples were fixed in 1\% paraformadehyde in PBS for 1 $\mathrm{hr}$ at room temperature (RT). Whole-mounted tissues were incubated for $3 \mathrm{hr}$ at RT with hamster monoclonal anti-platelet endothelial cell adhesion molecule-1 (PECAM-1) antibody 1:1,000 (Chemicon International, Temecula, CA), or rabbit polyclonal anti-lymphatic vessel endothelial hyaluronan receptor-1 (LYVE-1) antibody 1:1000 (Upstate, Lake Placid, NY) after a blocking the fixed tissues with $5 \%$ donkey serum in PBST $(0.3 \%$ Triton X-100 in PBS) for $1 \mathrm{hr}$ at RT. Samples were incubated for $2 \mathrm{hrs}$ at RT with HRP-conjugated antihamster antibody 1:100 (Jackson ImmunoResearch, West Grove, PA) or HRP-conjugated anti-rabbit antibody, 1:100 (Amersham, Piscataway, NJ) and developed with 3,3'-diaminobenzidine (DAB) substrate kit according to manufacturer's instruction (Vector, Burlingame, CA). Samples were analyzed and photographed with a Zeiss Stemi SV6 stereomicroscope. For hematoxylineosin (H\&E) and immunofluorescent staining of tissue sections, Samples were fixed in acetone for overnight at $-20^{\circ} \mathrm{C}$. Samples were embedded in paraffin block after serial incubation with methyl benzoate and xylene for $30 \mathrm{~min}$ at RT. Paraffin blocks were cut in 5-10 $\mu \mathrm{m} \mathrm{sec-}$ tions using Microm HM 335E rotary microtome (IMEB Inc, San Marcos, CA). Tissue sections were blocked with $5 \%$ goat or donkey serum in TBST $(0.03 \%$ Triton $\mathrm{X}-100$ in TBS) after dissolving the paraffin with xylene and acetone, immunostained with antibodies for $3 \mathrm{hr}$; 
these included hamster monoclonal anti-PECAM-1 antibody 1:200, rabbit polyclonal anti-LYVE-1 antibody $1: 200$, rat monoclonal anti-CD11b antibody 1:100 (BD Pharmingen, Franklin Lakes, NJ), rat monoclonal FITCconjugated anti-CD11b antibody 1:50 (BD Pharminogen), mouse monoclonal anti-Cytokeratin antibody (Abcam Inc, Cambridge, MA), rat monoclonal FITCconjugated anti-CD68 antibody 1:100 (Serotec Ltd., Oxford, UK), rat monoclonal anti-F4/80 antibody 1:100 (Research Diagnostics Inc., Flanders, NJ), goat polyclonal anti-VEGFR-3 antibody 1:100 (R\&D Systems, Inc., Minneapolis, $\mathrm{MN}$ ), goat polyclonal anti-VEGF-C antibody 1:100 (Santa Cruz Biotechnology, Inc.). After several washing steps using TBS, FITC-conjugated anti-hamster IgG antibody 1:1000, FITC-conjugated anti-rat IgG antibody 1:1000, FITC-conjugated anti-mouse IgG antibody 1:1000, Cy3-conjugated anti-rabbit IgG antibody 1:1000, Cy3-conjugated anti-rat IgG antibody 1:1000, Rhodamine-conjugated anti-goat IgG antibody 1:1000 were used as secondary antibodies. All secondary antibodies were purchased from Jackson ImmunoResearch Laboratories, Inc. Goat Fab fragment anti-mIgG (Jackson ImmunoResearch Laboratories, Inc.) was used to block endogenous mouse IgG to use mouse antibody on mouse tissue. Fluorescent signals were visualized and digital images were obtained using a Zeiss LSM 510 confocal microscope equipped with argon and heliumneon lasers (Carl Zeiss, Germany) or using a Zeiss ApoTome microscope coupled to a monochrome charge-coupled device camera (AxioVision, Carl Zeiss). Morphometric measurements of lymphatic and blood vessels in tumor and SLN were made from immunostained tissue sections by photographic analysis using ImageJ software (http://rsb.info.nih.gov/ij) after converting the images into 8-bit gray scale. Measurements of the number and size of the lymphatic vessels having lumen in tumor section were made at a screen magnification of $100 \times$, each $0.84 \mathrm{~mm}^{2}$ in area. Measurements of the densities of the blood vessels in tumor section were made at a screen magnification of $100 \times$, each 0.84 $\mathrm{mm}^{2}$ in area, whereas those and pan-cytokeratin stained cancer cells in SLN were made in total sectioned area (0.3-1.2 $\left.\mathrm{mm}^{2}\right)$, and 4 to 5 mice were used per group. To exclude background fluorescence, only pixels over a certain level (>50 intensity value) were taken. Measurements of the densities of the lymphatic vessels and blood vessels in the whole mount staining of bladder were made on whole fields at a screen magnification of $25 \times$, relative densities were calculated in each $1.16 \mathrm{~mm}^{2}$ in area, and 4-5 mice were used per group. Values were expressed as relative densities (\%). To measure the size of tumor and SLN, the mid-sectioned tissues were stained with H\&E. The stained tissues were photographed with a Zeiss microscope, surface areas of mid- sectioned tumor and SLN were calculated using a Zeiss Apotome microscope coupled to monochrome chargecoupled device (CCD) camera and image analysis software (AxioVision, Zeiss).

\section{Enrichment of CD11 $b^{+}$cells from OUBC by FACS and RT-PCR}

Single cell suspensions of OUBC were made by incubation with collagenase type IV (Worthington Biochemical Corporation, Lakewood, NJ) for $1 \mathrm{hr}$, and the suspended cells were washed with FACS buffer (Hank's Buffered Salt Solution (HBSS) $+4 \%$ bovine serum). The cells were incubated for $15 \mathrm{~min}$ with rat monoclonal PEconjugated anti-mouse CD11b antibody 1:250 (BD Pharmingen). Dead cells were excluded by staining with 7-amino-actinomycin D (7-AAD, Invitrogen, Carlsbad, CA). CD $11 b^{+}$cells and CD11b cells were enriched by a FACS Aria II (BD Biosciences) according to the manufacturer's instructions. The purities of subpopulations of

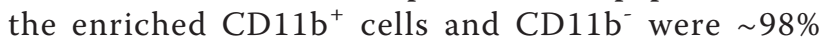
according to the FACS analysis. Total RNA from the enriched $\mathrm{CD}_{11 \mathrm{~b}^{+}}$cells and the CD11b cells and normal bladder were extracted using Trizol (Invitrogen) and Qiagen RNeasy micro kit (Qiagen, Valencia, CA) according to the manufacturer's instructions. Each cDNA was made with Superscript II reverse transcription system (Invitrogen). Quantitative RT-PCR was performed with the Prime Q-Mastermix (Genet bio, Chungnam, Korea) using the CFX96 ${ }^{\mathrm{TM}}$ Real-time PCR system (Bio-Rad, Hercules, CA). PCR reactions were performed with the appropriate primers (Table 1) for 60 cycles.

\section{Administration of blocking or depletion agent}

To block VEGF-C/D, the mice were treated with tail vein injections of $1.0 \times 10^{9}$ plaque-forming units $(\mathrm{pfu})$ of adenovirus encoding soluble VEGFR-3 (Ade-sVR3) $[25,26]$ twice on the day and two weeks after the MBT-

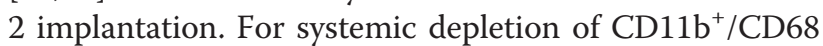
+ TAM, the mice were treated with intraperitoneal injections of clodronate liposome (CDL, $25 \mathrm{mg} / \mathrm{kg}$ every 3 days i.p.) as previously described at 2 weeks after the tumor implantation [22]. As a negative control, empty control liposome (CL) was injected in the same manner.

\section{Table 1 Primers for real-time RT-PCR}

\begin{tabular}{ccc}
\hline Genes & \multicolumn{2}{c}{ Primer Sequences } \\
\hline VEGF-C & Forward & 5'-CGT TCT CTG CCA GCA ACA TTA CCA C-3' \\
\cline { 2 - 3 } & Reverse & 5'-CTT GTT GGG TCC ACA GAC ATC ATG G-3' \\
\hline VEGF-D & Forward & 5'-GTC TGT AAA GCA CCA TGT CCG GGA G-3' \\
\cline { 2 - 3 } & Reverse & 5'-CCA CAG GCT GGC TTT CTA CTT GCA C-3' \\
\hline \multirow{2}{*}{ HPRT } & Forward & 5'-CCT CAT GGA CTG ATT ATG GAC A-3' \\
\cline { 2 - 3 } & Reverse & 5'-ATG TAA TCC AGC AGG TCA GCA A-3' \\
\hline
\end{tabular}


Statistical analysis

Values presented are means \pm standard deviation (SD). Significant differences between means were determined by Student's $t$-test or analysis of variance followed by the Student-Newman-Keuls test. The accepted level of statistical significance was $\mathrm{p}<0.05$.

\section{Results}

OUBC presents profound lymphangiogenesis, angiogenesis and TAM infiltration in tumor mass

Four weeks after the intravesical injection of MBT-2 cells, the lumen of urinary bladder was filled 70-80\% with the primary tumor mass $(\mathrm{n}=12)$ (Figure $1 \mathrm{~A}$ upper). In H\&E staining, the tumor invaded the mucosa, submucosa, and muscle layer of bladder wall, which means that OUBC is an invasive bladder tumor model, and not a superficial bladder tumor (Figure 1A lower, Additional File 1). Lymphatic and blood vessels were identified by immunofluorescence staining for LYVE-1 (specific marker for lymphatic endothelial cells) and PECAM-1 (specific marker for blood endothelial cells) in sectioned samples of OUBC and control mice. Lymphatic and blood vessels in OUBC were robust and tortuous, and were densely compacted (Figure 1B). The overall number and size of the lymphatic vessels in the bladder wall were increased in OUBC compared to the control (Figure $1 \mathrm{C}$ ), and the density of those vessels was $\sim 3.0$-fold higher in OUBC as well (Figure 1D). CD11b ${ }^{+}$, $\mathrm{CD} 68^{+}$or $\mathrm{F} 4 / 80^{+}$TAM was largely infiltrated around lymphatic vessels of tumor mass (Figure $1 \mathrm{E}$ ). In the $\mathrm{CD}_{11 \mathrm{~b}}{ }^{+} \mathrm{TAM}, 93 \pm 5 \%(\mathrm{n}=5)$ was $\mathrm{CD}^{+} 8^{+}$and $72 \pm$ $6 \%(\mathrm{n}=5)$ was $\mathrm{F} 4 / 80^{+}$cell (Additional File 2$)$. Thus,

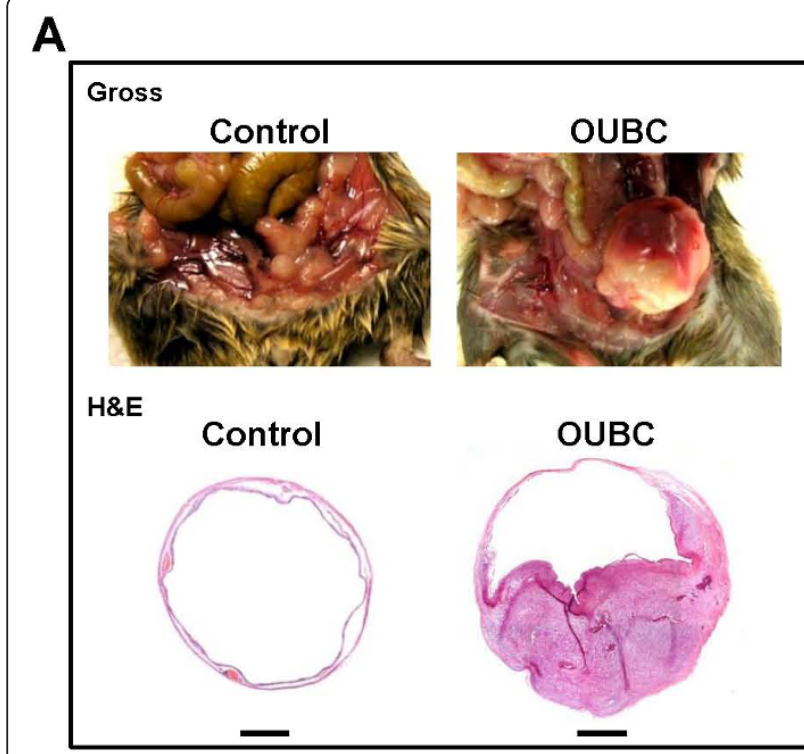

D

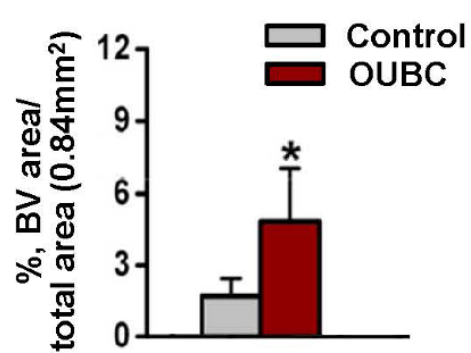

E

\section{B}

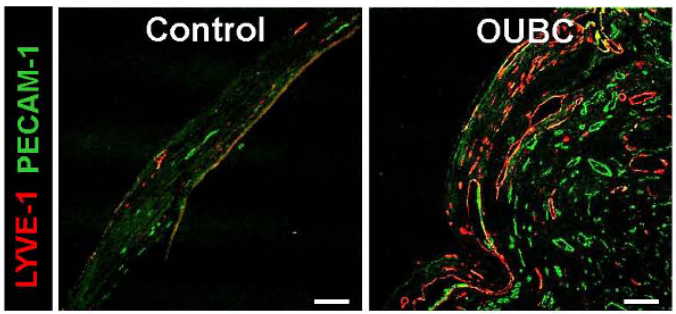

C

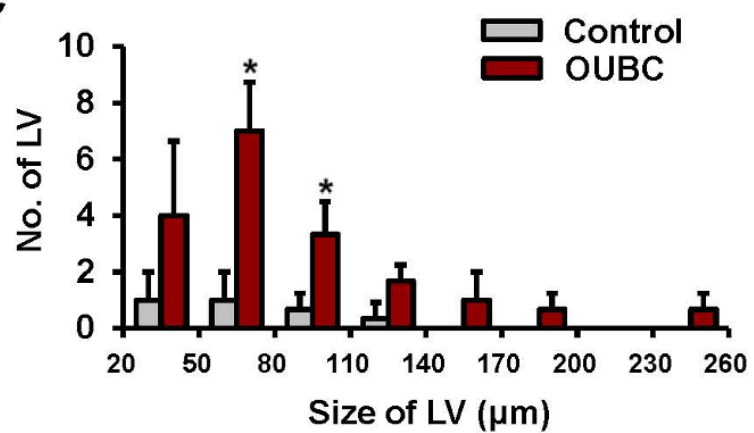

Figure 1 OUBC presents profound lymphangiogenesis, angiogenesis and CD11 b $\mathbf{b}^{+} / \mathrm{CD} \mathbf{8}^{+}$TAM infiltration. PBS (Control) or $1 \times 10^{6} \mathrm{MBT}-2$ cells (OUBC) were injected into the urinary bladders of 8-10-week old female $\mathrm{C} 3 \mathrm{H}$ mice. 4 weeks after PBS or the tumor cell injection, the bladders were harvested and stained. (A) Photos and images showing gross features and sections (H\&E stained) of bladders. Scale bars, 2 mm. (B) Images showing LYVE-1 $1^{+}$lymphatic vessels (LV) and PECAM-1+ blood vessels (BV). Scale bars, $100 \mu \mathrm{m}$. (C) Comparison of LV numbers at different sizes of $L V$ in the bladder sections. Graph shows mean $\pm S D ; n=5$ for each group. ${ }^{*} p<0.05$ versus Control. (D) Comparison of blood vessel densities (BVD) per total sectioned area $\left(0.84 \mathrm{~mm}^{2}\right)$ of bladder. Graph shows mean \pm SD; $n=5$ for each group. ${ }^{*} p<0.05$ versus Control.

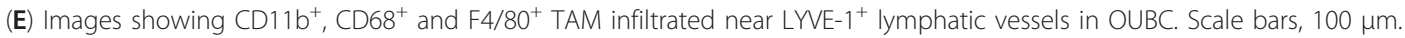


TAM adjacent to lymphatic vessels in OUBC was mainly $\mathrm{CD} 11 \mathrm{~b}^{+} / \mathrm{CD} 68^{+} / \mathrm{F} 4 / 80^{+} / \mathrm{LYVE}^{-} 1^{-}$cell.

\section{OUBC displays marked lymphatic enlargement and increased number of blood vessels in the peritoneal surface of bladder wall}

To examine changes in lymphatic and blood vessels in the peritoneal surface of bladder, the samples were whole mounted and immunostained for LYVE-1 or PECAM-1. Compared to the control, lymphatic vessels on the peritoneal surface were largely and variably enlarged, and the number of blood vessels was higher in the OUBC (Figure 2A). The densities of lymphatic and blood vessels were 2.6- and 3.5-fold higher, respectively in the OUBC $(\mathrm{n}=5)$ than the control $(\mathrm{n}=4)$ (Figure $2 \mathrm{~B})$.

\section{OUBC showed lymphatic metastasis of cancer cells to medial iliac lymph node}

To examine the lymphatic spread of OUBC-derived cancer cells to the lymph node, we harvested the medial iliac lymph node that lies just above the aortic bifurcation site (Figure 3A) as SLN at 4 weeks after the MBT-2 cell injection. In the OUBC, sizes of SLNs were substantially larger ( $\sim 3.8$ fold) than those of control mice, and the structures were significantly disorganized (Figure 3B, C, and 3D).
The densities of the lymphatic vessels in the medial iliac lymph nodes in the OUBC were $\sim 2.3$ fold higher than those of the control, whereas the densities of the blood vessels in SLN did not differ significantly from those of the control mice (Figure 3E left and 3F). To search for metastatic tumor cells out in SLN, sections of the lymph node were immunofluorescence stained with pan-cytokeratin, which is a useful marker for detecting of majority of epithelial-origin carcinomas $[27,28]$. There were many pan-cytokeratin stained cells in the medial iliac lymph nodes of all OUBC mice (Density: $7.0 \pm 1.3 \%, n=5$ ), while there were no pan-cytokeratin stained cells in the lymph node of control mice $(\mathrm{n}=4)$ (Figure $3 \mathrm{E}$ right and $3 \mathrm{G})$. Higher magnification image revealed that metastatic tumor cells congregated closely around lymphatic vessels in the SLN (Figure 3E lower right), indicating that the OUBC induces profound lymphatic metastasis of tumor cells from the primary tumor mass to the SLN.

\section{VEGFR-3 expressing CD11 $b^{+}$TAM is the source of VEGF-C/D}

The result of quantitative reverse transcription-polymerase chain reaction (qRT-PCR) assay revealed that expression levels of VEGF-C/D in bladder tumor mass are much higher than those of normal bladder by 258.3 times and 321.0 times, respectively. To investigate the source and

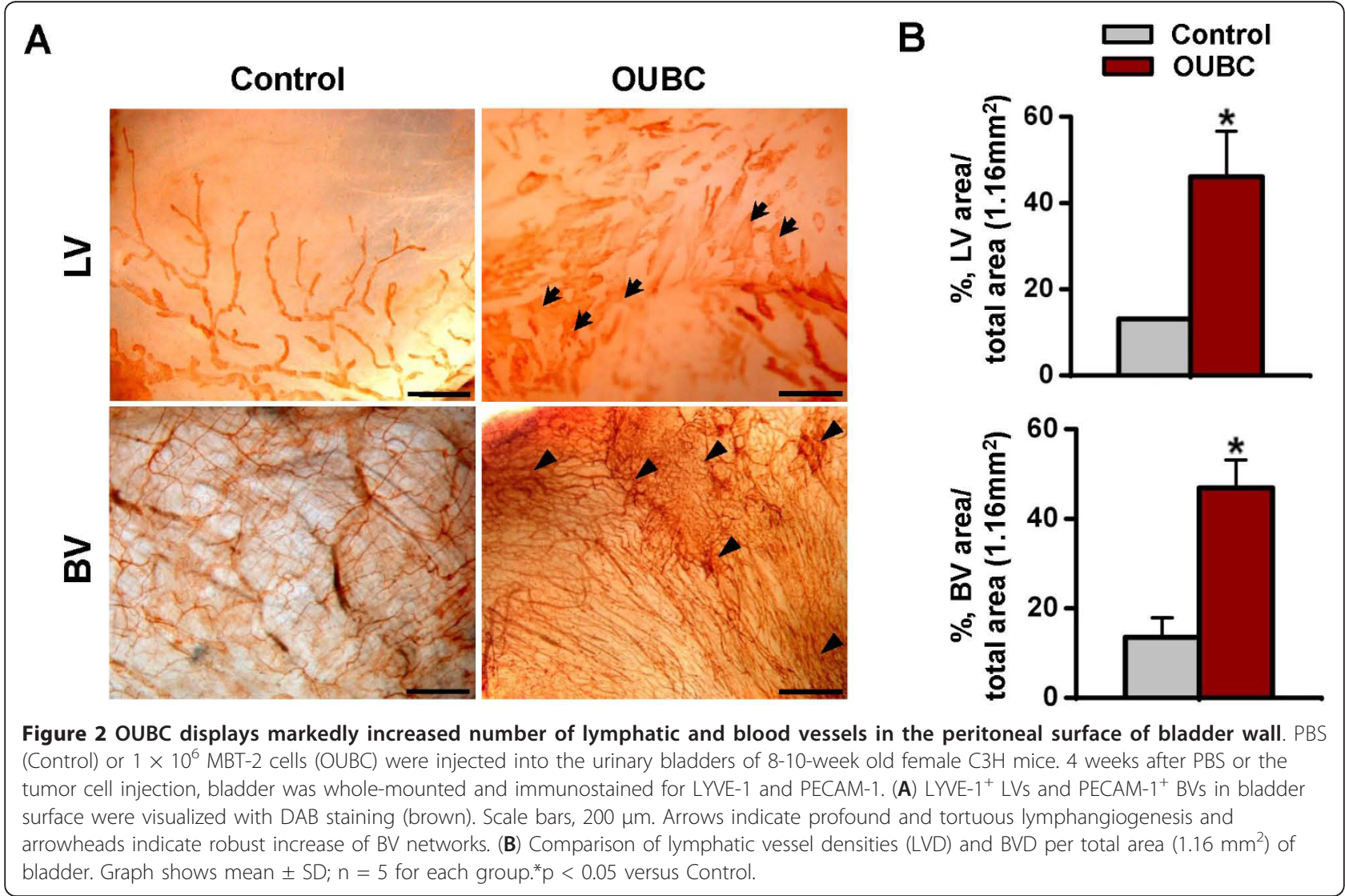




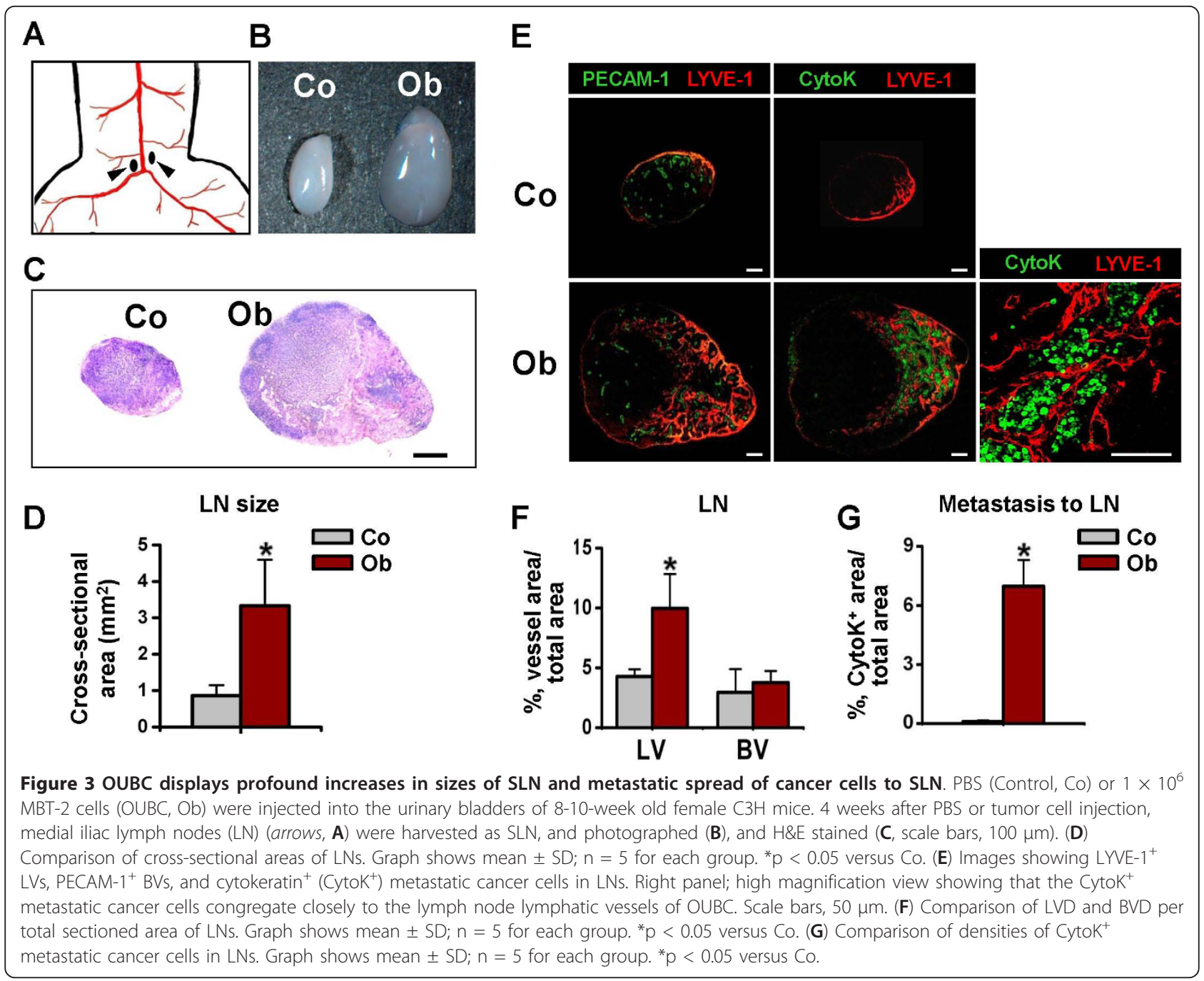

expression of VEGF-C/D that drive OUBC-induced lymphangiogenesis, we performed a series of qRT-PCR assays in the CD11b ${ }^{+}$TAM enriched by fluorescent activated cell sorter (FACS) from OUBC (Figure 4A). qRT-PCR analysis revealed that enriched $\mathrm{CD} 11 \mathrm{~b}^{+}$TAM expressed higher amount of VEGF-C (3.3-fold) and VEGF-D (2.0-fold) when compared to the CD11 b cells in bladder tumor mass (Figure 4B). Co-immunostaining analysis showed

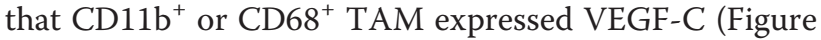
$4 C$ upper). Moreover, VEGFR-3 was highly expressed not only in the lymphatic vessels but also in the $\mathrm{CD}_{11 \mathrm{~b}^{+} \text {or }}$ $\mathrm{CD}^{+} 8^{+} \mathrm{TAM}$ of the OUBC (Figure $4 \mathrm{C}$ lower).

Blockade of VEGF-C/D by soluble extracellular domain of VEGFR-3 suppressed OUBC-induced lymphangiogenesis and lymphatic metastasis to SLN but not CD11b ${ }^{+}$TAM recruitment

To investigate the effects of VEGF-C/D in the OUBC, soluble extracellular domain of VEGFR-3 (sVR3) was overexpressed by systemic adenoviral delivery (hereafter referred as 'Ade-sVR3') [29] ( $\mathrm{n}=5)$. As a control, same amount of Ade- $\beta$ gal was treated in the same manner ( $\mathrm{n}$ =4). At four weeks after the cancer cell implantation, the number of the lymphatic vessels in tumor treated with Ade-sVR3 showed significant decrease of $65 \%$ over that of Ade- $\beta$ gal-treated tumor (Figure $5 \mathrm{~B}$ and $5 \mathrm{D}$ ). However, there were no significant changes in the growth of tumor sizes and the densities of blood vessels between the Ade-sVR3 versus the Ade- $\beta$ gal (Figure $5 \mathrm{~A}$, $\mathrm{B}, \mathrm{C}$ and $5 \mathrm{E}$ ). It was noted that blockade of VEGF-C/DVEGFR3 signaling is effective in disrupting lymphangiogenesis in bladder tumor. Furthermore, distribution densities of $\mathrm{CD}_{11 \mathrm{~b}^{+}}$TAM in OUBC were indistinguishable between Ade-sVR3 and Ade- $\beta$ gal, suggesting that VEGF-C/D signaling has no effect on the recruitment of $\mathrm{CD}_{11 b^{+}}$TAM into the OUBC (Figure 5F). In SLN, the Ade-sVR3 significantly decreased densities of lymphatic vessels, but not blood vessels (Figure 5G and 5H). 


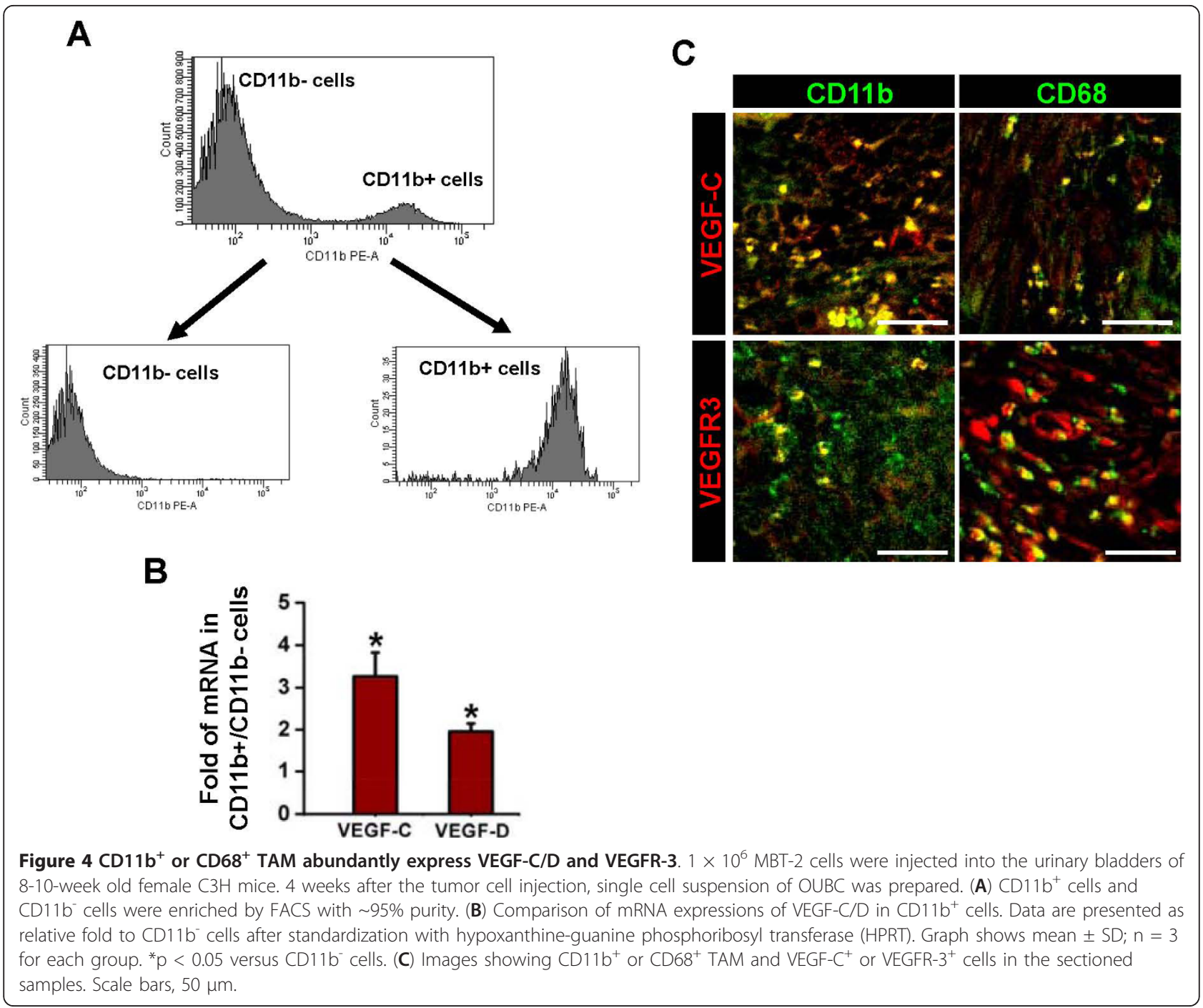

Importantly, metastatic cancer cells in SLN were decreased by $60 \%$ in the Ade-sVR3 compared to the Ade- $\beta$ gal (Figure $5 \mathrm{I}$ ), indicating that blockade of VEGFC/D by Ad-sVR3 strongly suppressed lymphatic metastasis to SLN.

\section{CD11 $b^{+}$TAM plays a crucial role in OUBC-induced lymphangiogenesis}

To clarify the role of infiltrating CD $11 \mathrm{~b}^{+}$TAM in the OUBC-induced lymphangiogenesis and angiogenesis, we depleted macrophages, including $\mathrm{CD}_{11} \mathrm{~b}^{+}$TAM, systemically by using the treatment of clodronate liposome (CDL) $[30,31](\mathrm{n}=5)$. As a control, control liposome $(C L)$ was treated in the same manner $(n=4)$. Two weeks after the CDL treatment, more than $90 \%$ of

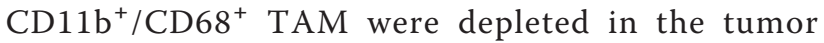
region of the OUBC, whereas the CL treatment did not

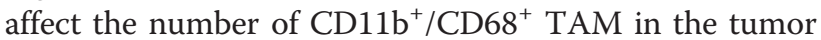

(Additional File 3). Although tumor sizes were indistinguishable between $\mathrm{CDL}$ treatment versus the $\mathrm{CL}$ treatment (Figure 6A and 6C), the CDL treatment decreased the number of lymphatic vessels in bladder tumor by $74 \%$ (Figure 6B and 6D). The CDL treatment also showed the tendency to decrease blood vessel densities, but it was not statistically significant (Figure 6B and 6E). These data suggest that $\mathrm{CD} 11 \mathrm{~b}^{+}$TAM plays a critical role in inducing lymphangiogenesis in the OUBC.

Lymphatic metastasis of the OUBC was strongly inhibited by depletion of $\mathrm{CD} 11 \mathrm{~b}^{+} \mathrm{TAM}$

To elucidate the role of $\mathrm{CD}_{11 \mathrm{~b}^{+}} \mathrm{TAM}$ in lymphatic metastasis in the OUBC, the SLN of CDL and CL treated mice were examined. Treatment with CDL, but not $\mathrm{CL}$, reduced the growth of lymphatic and blood vessels in the SLN (Figure 6F left). The densities of lymphatic and blood vessels in the SLN were decreased by about 


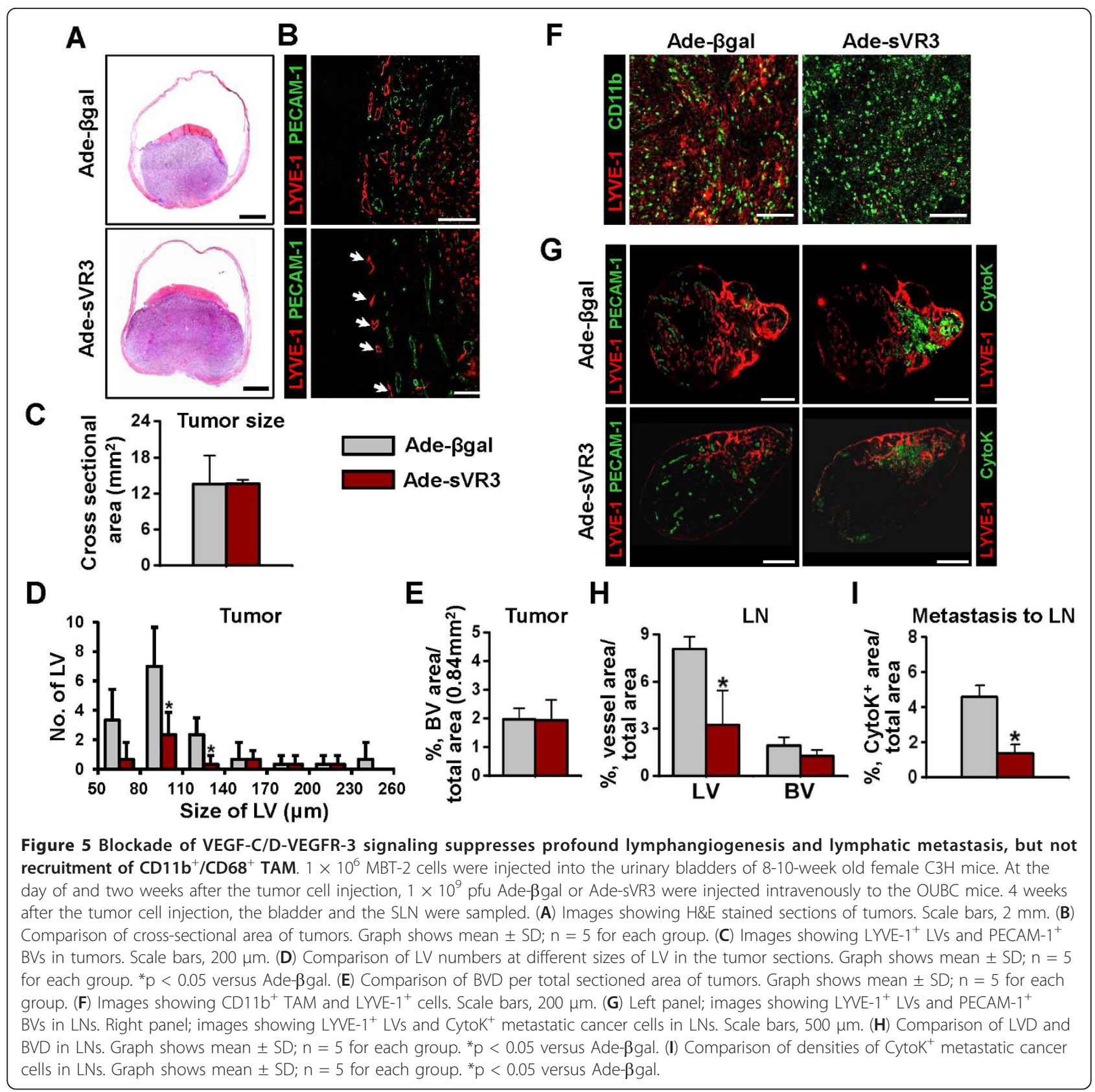

$30 \%$ and $40 \%$ in the CDL treatment compared to the CL treatment, respectively (Figure 6G). The lymphatic metastasis to the SLN was remarkably decreased by $70 \%$ in the CDL treated group when compared to the CL treated control group (Figure $6 \mathrm{~F}$ right and $6 \mathrm{H}$ ), indicating that $\mathrm{CD}_{11 \mathrm{~b}^{+}}$TAM play crucial role in lymphatic metastasis of bladder cancer cells.

\section{Discussion}

To establish distant metastasis, bladder tumor cells spread from the bladder to target organs through three main routes: hematogenous spread, lymphatic spread, and direct seeding. In bladder cancer, lymph node was known as the most common site of metastasis. Nearly $70 \%$ of bladder cancer patients experience lymphatic metastasis in the course of disease progression [2]; thus, lymph node metastasis is an important initial step toward distant metastasis [32].

In present study, OUBC model was an invasive bladder cancer which invades all layers of bladder wall and displayed profound lymphangiogenesis in primary tumor mass and SLN. Because TAM is known to play an important role in tumor lymphangiogenesis by secreting lymphangiogenic growth factor in other type of cancers 


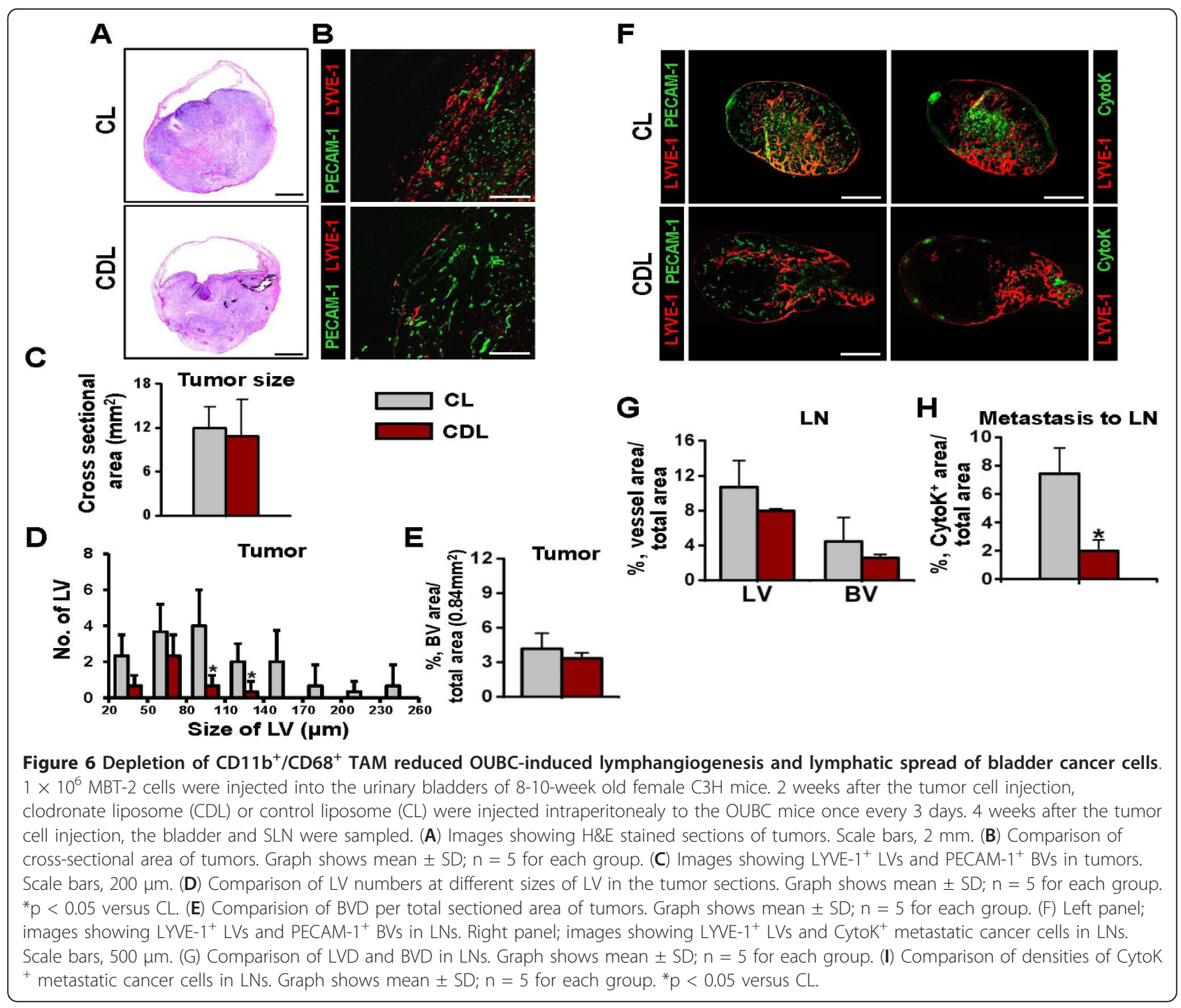

[20-22], we proposed that profound lymphangiogenesis is associated with TAM, and bladder cancer cells can actively metastasize through lymphatic vessels with the help of TAM. In fact, one previous report indicates that TAM is frequently observed in clinical samples of bladder cancer [33], and that patients with high TAM count showed higher frequencies of vascular invasion and distant metastasis, and have lower 5-year survival rates than those with low TAM count. Moreover, the TAM count and microvessel densities were positively correlated to each other. Indeed, the present study showed that there are massive infiltration of $\mathrm{CD}_{11} \mathrm{~b}^{+}$macrophages located near the lymphatic vessels in primary tumor and SLN. Moreover, immunofluorescence staining for the markers such as CD68 and F4/80 revealed that most of TAM is the tumor and metastasis-promoting M2-type [17].

The depletion of TAM by using CDL dramatically decreased the lymphangiogenesis in tumor and SLN and suppressed lymphatic metastasis of tumor cells to SLN, indicating that TAM is an important pro-lymphangiogenic and pro-metastatic modulator in the bladder tumor. In addition to increasing the number of lymphatic vessels, TAM is able to condition the vessels to be vulnerable to intravasation of tumor cells: TAM facilitates migration and intravasation of tumor cells by secreting growth factors and chemotactic factors, and by remodeling the extracellular matrix through collagen fibril formation [34]. Therefore, in the present study, it was possible that the anti-metastatic effect of CDL treatment might have resulted from not only the suppression of TAM-induced angiogenesis and lymphangiogenesis, but also from the inhibition of TAM-induced tumor cell migration and intravasation. However, contrary to previous report [31], depletion of TAM by CDL did not significantly reduce the tumor mass in the bladder. This could have resulted from the different characteristics of 
tumors in growing different organs. This orthotopic tumor grows mainly into the bladder cavity without invading its supporting tissues, a growth pattern that is quite different from that of other solid tumors.

Interestingly, $\mathrm{CD} 11 \mathrm{~b}^{+} / \mathrm{CD} 8^{+} \mathrm{TAM}$ expresses higher levels of VEGF-C/D than CD11b- cells, which were also known as the main mediator of tumor-associated lymphangiogenesis and lymphatic metastasis. Because

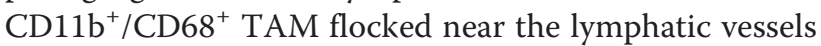
and VEGFR-3 was highly expressed in the lymphatic vascular endothelial cells, TAM could assist tumor-induced lymphangiogenesis by paracrine secretion of VEGF-C/D in bladder cancer. Moreover, co-immunostaining results showed that VEGFR-3 is also highly expressed in the $\mathrm{CD}_{11 \mathrm{~b}^{+}}$TAM in itself, indicating that TAM may have autocrine and paracrine positive feedback loop to boost further secretion of VEGF-C/D. Consequently, once TAM is activated to become M2-type, it could accelerate lymphangiogenesis and lymphatic metastasis by the paracrine and autocrine mechanism. From this study, we could not exclude the partial contribution of tumor cells to the source of VEGF-C/D. Nevertheless, we were able to exclude the idea that tumor cells are the main source of tumor lymphangiogenesis, because depletion of macrophages by the CDL treatment caused $>80 \%$ reduction in VEGF-C/D expressions in the tumor mass compared to the control CL treatment.

In addition, present data also indicate that the suppression of VEGF-C/D signaling by adenoviral delivery of sVR3 significantly reduced the growth of lymphatic vessels in bladder tumor and SLN and eventually inhibited lymphatic metastasis of bladder tumor cells from primary tumor to SLN without significant reductions of tumor mass and blood vessels in OUBC. These findings are mostly consistent with previously reported findings in the different tumor models [11-13]. Therefore, we postulated that lymphatic spread of cancer metastasis in patients with bladder cancer can be prevented by specific suppression of VEGF-C/D-VEGFR3 signaling pathways. But, this strategy seemed to have a limitation when reducing preformed tumor burden. In other words, because blocking lymphangiogenesis is rather tumoristatic than tumoricidal, blocking VEGF-C/D might be particularly useful when tumor burden is minimal, for example in the postoperative adjuvant setting. In comparison, recent studies $[35,36]$ show that VEGFR3 is upregulated in the tumor vasculature; also, loss-offunction studies by genetic targeting of VEGFR-3 or blocking of its signaling with monoclonal antibodies resulted in decreased sprouting, indicating that VEGFR3 has a role in angiogenic sprouting formation. The discrepancies in responsiveness to VEGFR-3 blocking experiments could have resulted from the different expression level of VEGFR-3 in the tumor vasculatures in varying tumor models. Indeed, the vasculatures and the sizes of our bladder cancer models are not responsive to the soluble VEGFR-3 treatment, which might be due to the low expression of VEGFR-3 in the tumor vasculatures.

Until now, even after successful radical cystectomy and lymph node dissection, about $50 \%$ of bladder cancer patients eventually show recurrence and have poor survival [1]. For more than 30 years, there have been many efforts to reduce the recurrence of high-risk bladder cancer after curative surgery, however, numerous clinical trials failed to show conclusive evidence on the impact of adjuvant chemotherapy even by using the most toxic combination regimens [37]. Considering these facts, blocking VEGF-C/D pathway and lymphangiogenesis could be another attractive alternative to reduce the recurrence of bladder tumor after curative radical cystectomy.

\section{Conclusion}

In summary, a profound OUBC-induced lymphangiogenesis in primary cancer and SLN contribute to lymphatic metastasis by VEGF-C/D and VEGFR-3 signaling. Infiltrated $\mathrm{CD} 11 \mathrm{~b}^{+} / \mathrm{CD} 68^{+}$TAM is intensely involved in OUBC-induced lymphangiogenesis and lymphatic metastasis and therefore TAM could be the bridge between primary cancer and SLN. Our study, which shows the therapeutic inhibition of lymphangiogenesis, provides another therapeutic target to inhibit lymphatic metastasis and recurrence in patients with invasive bladder cancer.

\section{Additional material}

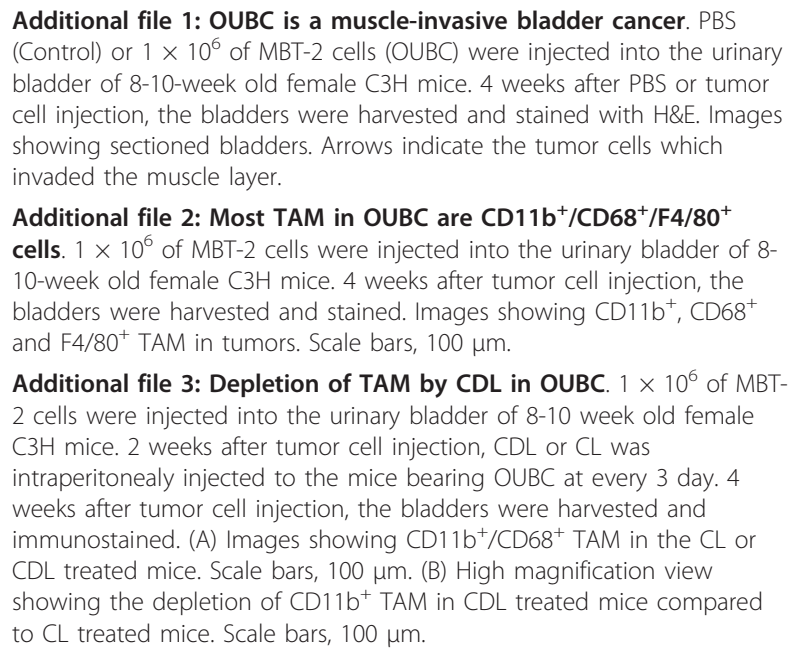

Acknowledgements

This work was supported by the grant (A092255, GYK) of the Korea Healthcare Technology R\&D Project, Ministry for Health, Welfare \& Family 
Affairs, Korea. We thank Dr. Warren Heston for MBT-2 cell line and Yuna Hong, Eun Soon Lee, and Tae Chang Yang for their technical assistance.

\section{Author details}

${ }^{1}$ National Research Laboratory of Vascular Biology and Graduate School of Medical Science and Engineering, Korea Advanced Institute of Science and Technology (KAIST), Daejeon, 305-701, Republic of Korea. ${ }^{2}$ Department of Urology, College of Medicine, Institute for Tumor Research, Chungbuk National University, Cheongju, 360-711, Republic of Korea. ${ }^{3}$ Laboratory of Liposome Research, Institute of Molecular Cancer Research, University of Zurich, Zurich, Switzerland. ${ }^{4}$ The Molecular/Cancer Biology Laboratory, Biomedicum Helsinki, University of Helsinki, Helsinki, Finland. ${ }^{5}$ Department of Cancer Biology, The Lerner Research Institute, The Cleveland Clinic Foundation, Cleveland, OH, USA.

\section{Authors' contributions}

HY, CK, WJK, KA and GYK designed and organized the experiments. WH provided MBT-2 cell line. HY, CK, MJK, and GYK performed the animal studies, analyzed the data, generated the figures, and histological analyses. RAS prepared materials for the experiments. HY, CK, WJK, WH and GYK wrote the manuscript. All authors read and approved the final manuscript.

\section{Competing interests}

The authors declare that they have no competing interests.

Received: 20 October 2010 Accepted: 11 April 2011

Published: 11 April 2011

\section{References}

1. Hussain S, James N: The systemic treatment of advanced and metastatic bladder cancer. The Lancet Oncology 2003, 4:489-497.

2. Shinagare AB, Ramaiya NH, Jagannathan JP, Fennessy FM, Taplin ME, Van den Abbeele AD: Metastatic Pattern of Bladder Cancer: Correlation With the Characteristics of the Primary Tumor. Am J Roentgen 2011, 196:117.

3. Bochner BH, Cote RJ, Weidner N, Groshen S, Chen SC, Skinner DG, Nichols PW: Angiogenesis in bladder cancer: relationship between microvessel density and tumor prognosis. J Natl Cancer Inst 1995, 87:1603-1612

4. Inoue K, Slaton JW, Karashima T, Yoshikawa C, Shuin T, Sweeney P, Millikan R, Dinney CP: The prognostic value of angiogenesis factor expression for predicting recurrence and metastasis of bladder cancer after neoadjuvant chemotherapy and radical cystectomy. Clin Cancer Res 2000, 6:4866-4873.

5. Fernandez MI, Bolenz C, Trojan L, Steidler A, Weiss C, Alken P, Grobholz R, Michel MS: Prognostic implications of lymphangiogenesis in muscleinvasive transitional cell carcinoma of the bladder. Eur Urol 2008, 53:571-578.

6. Saban MR, Towner R, Smith N, Abbott A, Neeman M, Davis CA, Simpson C, Maier J, Memet S, Wu XR, Saban R: Lymphatic vessel density and function in experimental bladder cancer. BMC Cancer 2007, 7:219.

7. Alitalo K, Tammela T, Petrova TV: Lymphangiogenesis in development and human disease. Nature 2005, 438:946-953.

8. Karpanen T, Alitalo K: Molecular biology and pathology of lymphangiogenesis. Annu Rev Pathol 2008, 3:367-397.

9. He $Y$, Karpanen T, Alitalo K: Role of lymphangiogenic factors in tumor metastasis. Biochim Biophys Acta 2004, 1654:3-12.

10. Hirakawa S, Brown LF, Kodama S, Paavonen K, Alitalo K, Detmar M: VEGF-Cinduced lymphangiogenesis in sentinel lymph nodes promotes tumor metastasis to distant sites. Blood 2007, 109:1010-1017.

11. Stacker SA, Achen MG, Jussila L, Baldwin ME, Alitalo K: Lymphangiogenesis and cancer metastasis. Nat Rev Cancer 2002, 2:573-583.

12. He Y, Kozaki K, Karpanen T, Koshikawa K, Yla-Herttuala S, Takahashi T, Alitalo K: Suppression of tumor lymphangiogenesis and lymph node metastasis by blocking vascular endothelial growth factor receptor 3 signaling. J Natl Cancer Inst 2002, 94:819-825.

13. Hoshida T, Isaka N, Hagendoorn J, di Tomaso E, Chen YL, Pytowski B, Fukumura D, Padera TP, Jain RK: Imaging steps of lymphatic metastasis reveals that vascular endothelial growth factor-C increases metastasis by increasing delivery of cancer cells to lymph nodes: therapeutic implications. Cancer Res 2006, 66:8065-8075.
14. Lin J, Lalani AS, Harding TC, Gonzalez M, Wu WW, Luan B, Tu GH, Koprivnikar K, VanRoey MJ, He Y, et al: Inhibition of lymphogenous metastasis using adeno-associated virus-mediated gene transfer of a soluble VEGFR-3 decoy receptor. Cancer Res 2005, 65:6901-6909.

15. Roberts N, Kloos B, Cassella M, Podgrabinska S, Persaud K, Wu Y, Pytowski B, Skobe M: Inhibition of VEGFR-3 activation with the antagonistic antibody more potently suppresses lymph node and distant metastases than inactivation of VEGFR-2. Cancer Res 2006, 66:2650-2657.

16. Miyata Y, Kanda S, Ohba K, Nomata K, Hayashida Y, Equchi J, Hayashi T, Kanetake H: Lymphangiogenesis and angiogenesis in bladder cancer: prognostic implications and regulation by vascular endothelial growth factors-A, -C, and -D. Clin Cancer Res 2006, 12:800-806.

17. Suzuki K, Morita T, Tokue A: Vascular endothelial growth factor-C (VEGF-C) expression predicts lymph node metastasis of transitional cell carcinoma of the bladder. Int J Urol 2005, 12:152-158.

18. Murdoch C, Muthana M, Coffelt SB, Lewis CE: The role of myeloid cells in the promotion of tumour angiogenesis. Nat Rev Cancer 2008, 8:618-631.

19. Lamagna C, Aurrand-Lions M, Imhof BA: Dual role of macrophages in tumor growth and angiogenesis. J Leukoc Biol 2006, 80:705-713.

20. Lewis CE, Pollard JW: Distinct role of macrophages in different tumor microenvironments. Cancer Res 2006, 66:605-612.

21. Iwata C, Kano MR, Komuro A, Oka M, Kiyono K, Johansson E, Morishita Y, Yashiro M, Hirakawa K, Kaminishi M, Miyazono K: Inhibition of cyclooxygenase-2 suppresses lymph node metastasis via reduction of lymphangiogenesis. Cancer Res 2007, 67:10181-10189.

22. Jeon BH, Jang C, Han J, Kataru RP, Piao L, Jung K, Cha HJ, Schwendener RA, Jang KY, Kim KS, et al: Profound but dysfunctional lymphangiogenesis via vascular endothelial growth factor ligands from CD11b+ macrophages in advanced ovarian cancer. Cancer Res 2008, 68:1100-1109.

23. Schoppmann SF, Birner P, Stockl J, Kalt R, Ullrich R, Caucig C, Kriehuber E, Nagy K, Alitalo K, Kerjaschki D: Tumor-associated macrophages express lymphatic endothelial growth factors and are related to peritumoral lymphangiogenesis. Am J Pathol 2002, 161:947-956.

24. Horiguchi Y, Larchian WA, Kaplinsky R, Fair WR, Heston WD: Intravesical liposome-mediated interleukin-2 gene therapy in orthotopic murine bladder cancer model. Gene Ther 2000, 7:844-851.

25. Karpanen T, Egeblad M, Karkkainen M, Kubo H, Yla-Herttuala S, Jaattela M, Alitalo K: Vascular endothelial growth factor $C$ promotes tumor lymphangiogenesis and intralymphatic tumor growth. Cancer Res 2001, 61:1786.

26. He Y, Rajantie I, Pajusola K, Jeltsch M, Holopainen T, Yla-Herttuala S, Harding T, Jooss K, Takahashi T, Alitalo K: Vascular endothelial cell growth factor receptor 3-mediated activation of lymphatic endothelium is crucial for tumor cell entry and spread via lymphatic vessels. Cancer Res 2005, 65:4739.

27. Jeffers MD, O'Dowd GM, Mulcahy H, Stagg M, O'Donoghue DP, Toner M: The prognostic significance of immunohistochemically detected lymph node micrometastases in colorectal carcinoma. J Pathol 1994, 172:183-187.

28. Cheng L, Montironi R, Davidson D, Lopez-Beltran A: Staging and reporting of urothelial carcinoma of the urinary bladder. Modern Pathology 2009, 22:570-595.

29. Makinen T, Jussila L, Veikkola T, Karpanen T, Kettunen MI, Pulkkanen K, Kauppinen R, Jackson DG, Kubo H, Nishikawa S, et al: Inhibition of lymphangiogenesis with resulting lymphedema in transgenic mice expressing soluble VEGF receptor-3. Nat Med 2001, 7:199-205.

30. Cho CH, Koh YJ, Han J, Sung HK, Jong Lee H, Morisada T, Schwendener RA, Brekken RA, Kang G, Oike Y, et al: Angiogenic role of LYVE-1-positive macrophages in adipose tissue. Circ Res 2007, 100:e47-57.

31. Zeisberger SM, Odermatt B, Marty C, Zehnder-Fjallman AH, Ballmer-Hofer K, Schwendener RA: Clodronate-liposome-mediated depletion of tumourassociated macrophages: a new and highly effective antiangiogenic therapy approach. Br J Cancer 2006, 95:272-281.

32. Rinderknecht $M$, Detmar M: Tumor lymphangiogenesis and melanoma metastasis. J Cell Physiol 2008, 216:347-354.

33. Hanada T, Nakagawa M, Emoto A, Nomura T, Nasu N, Nomura Y: Prognostic value of tumor associated macrophage count in human bladder cancer. International J Urol 2000, 7:263-269.

34. Qian BZ, Pollard JW: Macrophage diversity enhances tumor progression and metastasis. Cell 2010, 141:39-51. 
35. Tammela T, Zarkada G, Wallgard E, Murtomaki A, Suchting S, Wirzenius M, Waltari M, Hellstrom M, Schomber T, Peltonen R, et al: Blocking VEGFR-3 suppresses angiogenic sprouting and vascular network formation. Nature 2008, 454:656-660

36. Tvorogov D, Anisimov A, Zheng W, Leppanen VM, Tammela T, Laurinavicius S, Holnthoner W, Helotera $H$, Holopainen T, Jeltsch M, et al: Effective suppression of vascular network formation by combination of antibodies blocking VEGFR ligand binding and receptor dimerization. Cancer Cell 2010, 18:630-640.

37. Flechon A, Droz J: Chemotherapy practices and perspectives in invasive bladder cancer. Exp Rev Anticancer Thera 2006, 6:1473-1482.

doi:10.1186/1476-4598-10-36

Cite this article as: Yang et al: Soluble vascular endothelial growth

factor receptor-3 suppresses lymphangiogenesis and lymphatic

metastasis in bladder cancer. Molecular Cancer 2011 10:36.

\section{Submit your next manuscript to BioMed Central} and take full advantage of:

- Convenient online submission

- Thorough peer review

- No space constraints or color figure charges

- Immediate publication on acceptance

- Inclusion in PubMed, CAS, Scopus and Google Scholar

- Research which is freely available for redistribution

Submit your manuscript at www.biomedcentral.com/submit 